\title{
The association between sonographic enthesitis and radiographic damage in psoriatic arthritis
}

\author{
Ari Polachek', Richard Cook², Vinod Chandran³,4, Dafna D. Gladman ${ }^{6}$ and Lihi Eder ${ }^{7 *}$
}

\begin{abstract}
Background: To examine the association between sonographic enthesitis and the severity of radiographic features of damage in the peripheral and axial joints in psoriatic arthritis (PsA).

Methods: A cross-sectional analysis was conducted in patients with PsA. The MAdrid Sonography Enthesitis Index (MASEI) scoring system was used to quantify the extent of sonographic entheseal abnormalities. Radiographic damage in the peripheral joints and spine was assessed by the modified Steinbrocker score (mSS), Modified New York Criteria for sacroiliitis, and the modified Stoke Ankylosing Spondylitis Spine Score (mSASSS). The association between MASEl and the extent of radiographic damage was assessed using negative binomial and logistic regression. The results were expressed in terms of the regression coefficient estimates and their exponentiated values $\left(e^{\beta}\right)$ or odds ratios (OR), and 95\% confidence intervals (Cl).
\end{abstract}

Results: Two hundred and twenty three patients were analyzed; 58\% were males, with mean \pm SD age of $55.9 \pm 12$. 9 years and PsA duration of $16.7 \pm 12.4$ years. Regression analyses yielded an association between higher MASEl scores (10 units increase) and peripheral joint damage including $\mathrm{mSS}\left(\mathrm{e}^{\beta}=1.42,95 \% \mathrm{Cl}: 1.15,1.72\right)$, joint ankylosis (OR $=1.93$, $95 \%$ Cl: $1.37,2.72)$, arthritis mutilans ( $\mathrm{OR}=1.77,95 \% \mathrm{Cl}: 1.23,2.54)$, and periostitis $(\mathrm{OR}=1.41,95 \% \mathrm{Cl}: 1.08$, 1.84). Similarly, an association was found between higher MASEl scores and axial damage as measured by mSASSS $\left(e^{\beta}=2.18,95 \% \mathrm{Cl}\right.$ : $1.16,4.09)$ and sacroiliitis ( $\mathrm{OR}=1.33,95 \% \mathrm{Cl}: 1.03,1.72)$.

Conclusions: The severity of sonographic enthesitis is a potential marker of radiographic peripheral and axial joint damage in PsA.

Keywords: Spondyloarthritis, Pathogenesis, Ultrasound, Steinbrocker, Sacroiliitis, Spondylitis

\section{Background}

Psoriatic arthritis (PsA) is an inflammatory musculoskeletal disease affecting up to a third of psoriasis patients $[1,2]$. PsA can affect different locations including the synovial joint, bone, fat pad, bursa, adjacent tendons, and entheses [3]. Enthesitis is a unique feature of the spondyloarthritis (SpA) disease group in general, and of PsA in particular $[4,5]$. Clinical enthesitis is a common finding occurring in a third of PsA patients [6, 7].

There are a few imaging modalities that can assist in enthesitis assessment apart from physical examination.

\footnotetext{
* Correspondence: lihi.eder@wchospital.ca

${ }^{7}$ Department of Medicine, University of Toronto, Women's College Research Institute, Women's College Hospital, Room 6326, 76 Grenville Street, Toronto, ON M5S 1B2, Canada

Full list of author information is available at the end of the article
}

Conventional radiography, which usually shows erosions at the enthesis and enthesophytes [8], is limited by its ability to detect mainly chronic irreversible bone damage rather than active inflammation. Another modality is magnetic resonance imaging (MRI) that can demonstrate both active lesions, as entheseal thickness, soft tissue edema, and adjacent bone marrow edema, as well as chronic lesions including erosions and enthesophytes [9]. However, in a recent study that evaluated whole-body MRI, enthesitis was found in only $18 \%$ of the patients with PsA and the ability to read images from some locations was technically limited [10]. Musculoskeletal ultrasound (US) assessment is inexpensive, readily available, relatively easy to perform and can evaluate a number of entheseal locations in a short period of time [11]. Several studies 
found higher sensitivity and specificity of US assessment of the entheses compared with clinical examination [12-15]. Therefore, US has emerged as the preferred modality to assess enthesitis.

The primacy of enthesitis in the pathogenesis of SpA and PsA is a matter of debate. According to the synovioentheseal model, suggested by McGonagle et al. enthesitis is the initial site of musculoskeletal inflammation in SpA [16]. A few animal model studies support this hypothesis by reporting a link between mechanical stress, enthesitis, and the development of arthritis that is similar to PsA [17-19]. In addition, in a small study that followed 30 psoriasis patients for 3.5 years, the presence of sonographic features of thickness of the quadriceps tendon predicted the development of PsA [20]. However, overall there is limited information about the association between enthesitis and disease outcomes in patients with PsA. We hypothesized that since enthesitis play a role in the pathogenesis of PsA it may serve as a marker of more severe disease outcomes in PsA, alternatively, enthesitis may play a direct role in the development of joint damage in PsA.

Hence, the main objective of the present study was to examine the association between sonographic enthesitis and the severity of radiographic features of damage in the peripheral and axial joints in patients with PsA.

\section{Methods}

\section{Setting and study population}

A cross-sectional study of patients enrolled in the Toronto PsA cohort was conducted. The cohort consists of patients with PsA who are referred to the University of Toronto PsA clinic for the management of their PsA. The patients are enrolled in an ongoing prospective cohort study aimed at assessing prognostic factors in PsA. Each patient is assessed at 6-12-month intervals according to a standard protocol. For the present study, randomly available consecutive patients were recruited for a single ultrasound assessment. The recruitment was completed during two separated time periods: June 2011 to October 2012 (this group of patients participated in our previous study about enthesitis in PsA [21]) and January 2014 to December 2015. Patients were recruited independently of their clinical and radiographic information. All patients satisfied the Classification for Psoriatic Arthritis (CASPAR) criteria [22].

Information collected includes demographics, lifestyle habits including smoking, co-morbid conditions, medications, height, weight, counts of tender swollen and damaged joints, dactylitis, clinical enthesitis assessment according to the SPondyloArthritis Research Consortium Canada (SPARCC) index [22], psoriasis area and severity index (PASI) and the presence of psoriatic nail involvement. The study was approved by the University Health
Network Research Ethics Board. All patients signed an informed consent form.

\section{Ultrasound assessment of enthesitis}

A single rheumatologist (LE), who has 7 years of experience in musculoskeletal US and assessment of sonographic enthesitis, performed all US scanning using a MyLab 70 XVG scanner (Esaote, Florence, Italy) equipped with a 6-18 MHz linear transducer (Esaote). Power Doppler settings were standardized with a Doppler frequency of 8.3-10 MHz (depending on body habitus), pulse repetition frequency of $750 \mathrm{~Hz}$, and a wall filter of 2 . The following entheseal sites that are part of the MAdrid Sonographic Enthesitis Index (MASEI) scoring system were scanned bilaterally: quadriceps tendon insertion to the patella, patellar tendon insertion to the patella, and tibial tuberosity, Achilles tendon and plantar fascia insertions into the calcaneus, and triceps tendon insertion to the olecranon process. Each tendon was scanned in both longitudinal and transverse planes, and the scan images were stored as short video files for later reading. Each examination took about 20 minutes. The patients were placed in a supine position to assess the patellar and quadriceps entheses. The knee was placed in $30^{\circ}$ flexion to assess grayscale abnormalities and in full extension to assess vascularization. Then the patients were placed in a prone position with the feet over the end of the examination table for assessment of the Achilles tendon and plantar fascia entheses. The triceps tendon enthesis was assessed with the elbow flexed to $90^{\circ}$ [23].

The MASEI was used to generate a global score (range, 0-136) that reflects the severity of entheseal abnormalities in each patient [24]. The enthesopathy US grayscale features of this index include: thickening and structural changes of the tendon insertion, calcific deposits at the tendon insertion, bony changes including erosions and enthesophyte formation as defined by de Miguel et al. [24]. The thickness of the enthesis was measured at the insertion of the deeper tendon margin into the bone in a longitudinal axis. Bursitis was defined as a well circumscribed, localized anechoic or hypoechoic area at the site of an anatomical bursa, which was compressible by the transducer. Vascularization was assessed by the power Doppler within $2 \mathrm{~mm}$ of the cortical bone insertion. The sonographic elementary lesions described above are illustrated in Fig. 1. The total MASEI score was further categorized into: (1) bone score, including calcific deposits, erosions and enthesophytes and (2) soft tissue score, including thickening and structural changes of the tendon insertion, bursitis and vascularization. The categorization of sonographic enthesitis scores to chronic/ bone score and inflammatory/soft tissue score have been previously used by others [25]. Reading of the US scans was performed independently from the clinical 


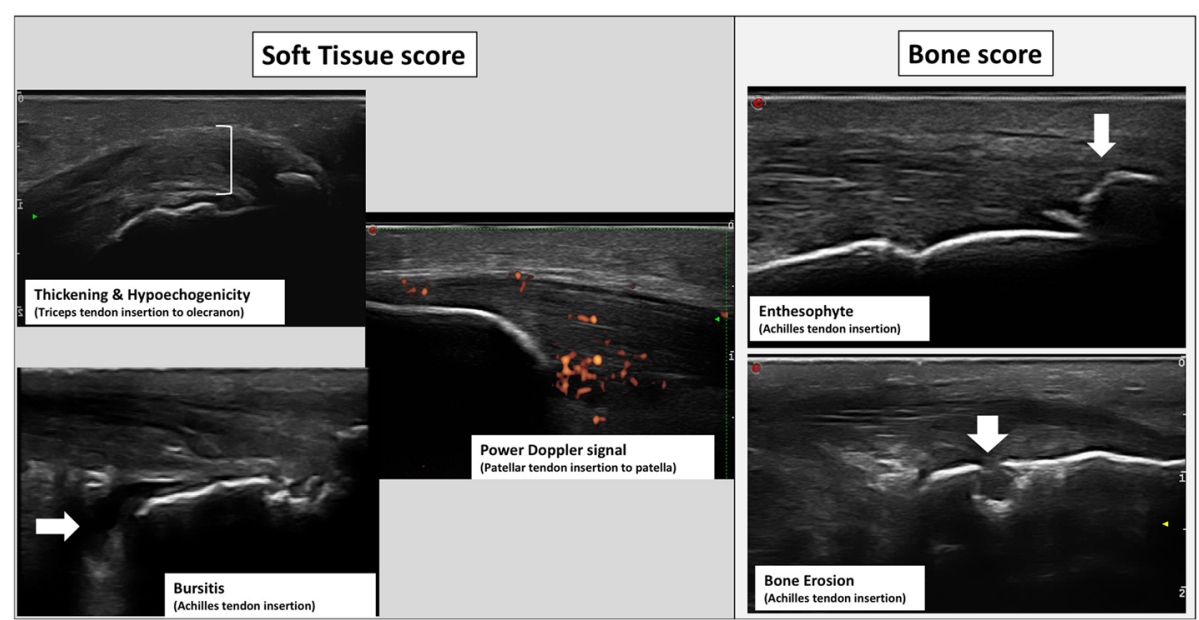

Fig. 1 Elementary lesions of enthesitis included in the Madrid Sonography Enthesitis Index (MASEI)

and radiographic data by a single reader (LE). The intra-observer intra-class correlation coefficient for MASEI was 0.8 [23].

\section{Radiographic joint damage assessment}

According to the Toronto PsA clinic protocol, conventional radiography assessment that includes hands, feet, spine, and sacroiliac joints is conducted every 2 years. The reading is performed by at least two rheumatology experts in PsA who were blinded to the US results (DDG, VC).

Peripheral joint damage in 42 joints of the hands and feet was assessed by the modified Steinbrocker score (mSS) [8]. According to this method each joint is scored on a scale ranging from 0 to 4: 0 for normal; 1 for juxtaarticular osteopenia or soft tissue swelling; 2 for erosion; 3 for erosion and joint space narrowing, and 4 for total joint destruction. The total $\mathrm{mSS}$ is the sum of all scores that are equal or greater than 2 (range 0-168). A score of 1 is not counted towards the total mSS; therefore only definite erosive damage is considered. This method is used to follow radiographic damage in our cohort as it has proved to be valid, reliable, sensitive to change, and feasible to perform in a clinic setting [8]. Additional radiographic features of peripheral joint damage recorded included joint ankylosis, arthritis mutilans that was defined as bone resorption affecting more than $50 \%$ of the joint and periostitis that was defined as juxta-articular new bone formation. Axial joint damage was assessed by the modified New York criteria for sacroiliitis [26] and the modified Stoke Ankylosing Spondylitis Spine Score (mSASSS) for spinal damage (score range 0-72) [27].

\section{Statistical analysis}

The analysis was restricted to patients with complete data. Continuous data were described by the mean \pm SD and categorical variables were expressed as frequencies and percentages. The association between MASEI score (by 10 units increase, the primary predictor) and the various radiographic features of joint damage (outcomes) was assessed through the use of negative binomial regression models [28] with count responses (mSS and mSASSS) and logistic regression for binary data (ankylosis, mutilans, sacroiliitis, and periostitis).

The initial regression model included only MASEI score as a single co-variate. Multiple regression analyses were then performed in which each regression model xadjusted for age, sex, body mass index (BMI), PsA duration, smoking (past, current, never), and current use of disease-modifying antirheumatic drugs (DMARDs) and biologic medications. A sensitivity analysis was performed with "ever use" instead of "current use" of DMARDs and biologics as model covariates. For negative binomial regression models the effect of MASEI score was expressed through its regression coefficient $(\beta)$ along with its exponential value $\left(\mathrm{e}^{\beta}\right)$ and their $95 \%$ confidence intervals $(\mathrm{CI})$; the exponentiated value $\mathrm{e}^{\beta}$ is interpreted as the multiplicative effect of 10 units change of MASEI score on the mean response while the other covariates remain unchanged. Odds ratios (OR) were used to express the effect of 10 units increase in the MASEI score in logistic regression models. The effect of a covariate was considered statistically significant if the $P$ value was less than 0.05 . The statistical analyses were performed using SAS version 9.4 (SAS Institute, Inc., Cary, NC, USA)

\section{Results}

\section{Baseline characteristics}

Two hundred and twenty-three patients were included in the analysis (nine patients were excluded due to missing data). Their mean age was $56 \pm 12.9$ years $(57.9 \%$ males) with a mean PsA duration of $16.9 \pm 12.4$ years (Table 1 ). Their mean tender and swollen joint counts were $2.5 \pm 5.3$ 
Table 1 Characteristics of the study population at the time of the assessment $(N=223)$

\begin{tabular}{|c|c|}
\hline Variable & Value \\
\hline \multicolumn{2}{|l|}{ Demographics: } \\
\hline Age (years), mean $\pm S D$ & $56 \pm 12.9$ \\
\hline Male gender, n (\%) & $129(57.9)$ \\
\hline PsA duration (years), mean \pm SD & $16.9 \pm 12.4$ \\
\hline Psoriasis skin disease duration (years), mean \pm SD & $28.1 \pm 14.5$ \\
\hline $\mathrm{BMI}$, mean $\pm \mathrm{SD}$ & $29.8 \pm 6.1$ \\
\hline \multicolumn{2}{|l|}{ Smoking } \\
\hline Current, n (\%) & $29(13)$ \\
\hline Past, n (\%) & $70(31.4)$ \\
\hline \multicolumn{2}{|l|}{ Clinical activity measures: } \\
\hline Tender joints count, mean \pm SD & $2.5 \pm 5.3$ \\
\hline Swollen joint count, mean \pm SD & $1.1 \pm 3.3$ \\
\hline Clinical enthesitis, n (\%) & $31(13.9)$ \\
\hline Dactylitis, n (\%) & $9(4)$ \\
\hline PASI, mean $\pm S D$ & $2.6 \pm 5.8$ \\
\hline Nail lesions, n (\%) & $59(26.4)$ \\
\hline $\mathrm{HLA}-\mathrm{B}^{*} 27$ & $34(15.5)$ \\
\hline \multicolumn{2}{|l|}{ Radiographic evaluation: } \\
\hline \multicolumn{2}{|l|}{ modified Steinbrocker score } \\
\hline mean $\pm S D$ & $18.7 \pm 33.6$ \\
\hline median $\left(25^{\text {th }}, 75^{\text {th }}\right.$ percentile $)$ & $4(0,20)$ \\
\hline Arthritis mutilans, n (\%) & $20(9)$ \\
\hline Joint ankylosis, n (\%) & $26(11.7)$ \\
\hline Periostitis, n (\%) & $49(22.2)$ \\
\hline \multicolumn{2}{|l|}{ mSASSS, } \\
\hline mean $\pm S D$ & $1.7 \pm 7.2$ \\
\hline median $\left(25^{\text {th }}, 75^{\text {th }}\right.$ percentile $)$ & $0(0,0)$ \\
\hline Sacroiliitis, n (\%), & $82(37.1)$ \\
\hline \multicolumn{2}{|l|}{ Sonographic evaluation: } \\
\hline MASEl, mean \pm SD & $15.7 \pm 12.6$ \\
\hline \multicolumn{2}{|l|}{ Treatment: } \\
\hline DMARDs - current use, n (\%) & $102(45.7)$ \\
\hline DMARDs - ever use, n (\%) & $181(81.2)$ \\
\hline Biologics - current use, n (\%) & $119(53.4)$ \\
\hline Biologics - ever use, n (\%) & $130(58.3)$ \\
\hline
\end{tabular}

PsA psoriatic arthritis, BMI body mass index, BODPASI psoriasis area and severity index, $H L A-B^{*} 27$ human leukocyte antigen $B * 27, m S A S S S$ modified Stoke Ankylosing Spondylitis Spine Score, MASEI MAdrid Sonography Enthesitis Index, DMARDs disease-modifying antirheumatic drugs

and $1.1 \pm 3.3$, respectively. Clinical enthesitis was found in $13.9 \%$ of the patients.

The mean MASEI score was $15.6 \pm 12.6$ and the mean $\mathrm{mSS}$ was $18.7 \pm 33.6$. With respect to axial radiographic damage, the mean mSASSS was $1.7 \pm 7.2$ and $37.1 \%$ of the patients had sacroiliitis.
The association between MASEI and peripheral radiographic damage

The results of the statistical analyses assessing the association between MASEI score and the various measures of peripheral joint damage are shown in Table 2. Multiple regression analysis yielded an association between MASEI score and mSS so that a 10-unit increase in MASEI was associated with a $42 \%$ higher $\mathrm{mSS}\left(\mathrm{e}^{\beta}=1.42,95 \%\right.$ CI 1.15 , 1.72). Both MASEI bone and soft tissue subscores were independently associated with mSS. In addition, an association was found between a MASEI score and additional outcomes of peripheral joint damage (Table 3). A higher MASEI score was also associated with ankylosis such that a 10-unit increase in MASEI almost doubled the odds of ankylosis (OR $=1.93,95 \%$ CI 1.37, 2.72). Similarly, both MASEI bone and soft tissue subscores were associated with this outcome. Finally, an association was found between MASEI score (10 units increase) and arthritis mutilans (OR 1.77, 95\% CI 1.23, 2.54) and periostitis (OR 1.41, 95\% CI 1.08, 1.84). When the components of the MASEI score were examined separately, only MASEI bone score was associated with these outcomes.

\section{The association between MASEI and axial radiographic damage}

The results of the regression models assessing the association between MASEI score and the various measures of axial joint damage are shown in Table 3 and 4. Multiple regression analyses yielded an association between a higher MASEI score (10 units increase) and mSASSS $\left(\mathrm{e}^{\beta} 2.18,95 \%\right.$ CI 1.16, 4.09). Both the MASEI bone and soft tissue subscores were associated with higher mSASSS scores. In addition, an association was found between a higher MASEI score (10 units increase) and the presence of sacroiliitis (OR 1.33, 95\% CI 1.03, 1.72). MASEI bone subscore was associated with sacroiliitis, but the MASEI soft tissue subscore was not.

\section{Sensitivity analysis}

In a sensitivity analysis, the model covariates "current use of DMARDs" and "current use of biologics" were replaced by "ever use of DMARDs" and "ever use of biologics". No significant changes in the results were observed (data not shown).

\section{Discussion}

It was Ball in 1971 who primarily set the foundations for the significance of enthesitis in SpA, by suggesting that the enthesis is centrally affected in ankylosing spondylitis (AS) patients, while the synovial joint is the main target of the inflammatory involvement in rheumatoid arthritis (RA) patients [29]. A few decades later, McGonagle and colleagues contributed significantly to the understanding of enthesitis as a key feature in SpA [16, 30]. Over 
Table 2 The association between MASEI and modified Steinbroker score - negative binomial regression

\begin{tabular}{|c|c|c|c|c|c|c|}
\hline \multirow[t]{2}{*}{ Variable $^{*}$} & \multicolumn{3}{|c|}{ Univariate regression } & \multicolumn{3}{|c|}{ Multiple regression $^{* *}$} \\
\hline & estimate (SE) & $\exp ^{\text {(Estimate) }}(95 \%$ Cl) & $P$ value & estimate (SE) & $\exp ^{\text {(Estimate) }}(95 \%$ Cl) & $P$ value \\
\hline MASEI - total & $0.48(0.11)$ & $1.61(1.30,1.99)$ & $<0.001$ & $0.35(0.10)$ & $1.42(1.15,1.73)$ & $<0.001$ \\
\hline MASEI - bone score & $0.86(0.19)$ & $2.36(1.63,3.38)$ & $<0.001$ & $0.64(0.18)$ & $1.89(1.33,2.69)$ & $<0.001$ \\
\hline MASEI - soft tissue score & $0.63(0.20)$ & $1.88(1.26,2.77)$ & 0.002 & $0.37(0.18)$ & $1.44(1.03,2.05)$ & 0.03 \\
\hline
\end{tabular}

MASEI MAdrid Sonography Enthesitis Index

*10 units increase in MASEI

**Each model was adjusted for age, sex, PsA duration, BMI, smoking, current use of DMARDs and biologics

the years, this idea was recognized by different organizations as the Assessment of Spondyloarthritis International Group (ASAS) that included it in their classification criteria for both axial and peripheral SpA and by the Group for Research and Assessment of Psoriasis and Psoriatic Arthritis (GRAPPA) who included it in the stem requirements of the CASPAR criteria [21, 31, 32].

The current study provides novel data regarding the association between enthesitis and features of severity in patients with PsA. The study found that a higher MASEI score, which reflects more severe enthesitis, is associated with severity of peripheral radiographic joint damage as measured by mSS. Furthermore, the severity of enthesitis was associated with proliferative and erosive features of joint damage including joint ankylosis, arthritis mutilans and periostitis. Additionally, a higher enthesitis score was associated with features of axial radiographic damage, including syndesmophytes and sacroiliitis.
According to the synovio-entheseal complex model, enthesitis is the primary lesion that triggers the related inflammation in the adjacent synovial joint [16]. This hypothesis is supported by a study that compared early SpA to early RA patients and demonstrated that knee synovitis was associated with entheseal abnormalities only in the SpA group [33]. Additional studies from the same group found associations between enthesitis and various features of $\mathrm{SpA}$ as dactylitis, tenosynovitis, arthritis mutilans, distal interphalangeal joint involvement, and psoriatic nail disease [34]. Supporting the importance of enthesitis in peripheral musculoskeletal inflammation in PsA, other studies that compared PsA and RA patients found that sonographic entheseal abnormalities in the fingers were identified only in the PsA group [4, 5]. Finally, a recent study in transgenic TNF $\alpha$ mice demonstrated that the initial signs of inflammation were found at the entheses and subsequently new bone formation appeared at entheseal sites and correlated with

Table 3 The association between MASEI score and features of radiographic damage - Logistic regression analysis

\begin{tabular}{|c|c|c|c|c|}
\hline \multirow[t]{2}{*}{ Variable* } & \multicolumn{2}{|c|}{ Univariate regression } & \multicolumn{2}{|c|}{ Multiple regression $^{* *}$} \\
\hline & OR $(95 \% \mathrm{Cl})$ & $P$ value & OR $(95 \% \mathrm{Cl})$ & $P$ value \\
\hline \multicolumn{5}{|l|}{ Joint ankylosis } \\
\hline MASEI total & 2.05 (1.52 2.75) & $<0.001$ & $1.93(1.37,2.72)$ & $<0.001$ \\
\hline MASEI - bone score & $3.49(2.09,5.85)$ & $<0.001$ & $3.24(1.75,6.01)$ & $<0.001$ \\
\hline MASEI - soft tissue score & $2.59(1.55,4.31)$ & $<0.001$ & $2.96(1.36,4.22)$ & 0.003 \\
\hline \multicolumn{5}{|l|}{ Arthritis mutilans } \\
\hline MASEI total & $1.96(1.43,2.69)$ & $<0.001$ & $1.77(1.23,2.54)$ & 0.002 \\
\hline MASEI - bone score & $3.94(2.24,6.93)$ & $<0.001$ & $3.77(1.84,7.70)$ & $<0.001$ \\
\hline MASEI - soft tissue score & $2.00(1.15,3.50)$ & 0.014 & $1.71(0.90,3.26)$ & 0.102 \\
\hline \multicolumn{5}{|l|}{ Periostitis } \\
\hline MASEl total & $1.48(1.17,1.88)$ & 0.001 & $1.41(1.08,1.84)$ & 0.013 \\
\hline MASEI - bone score & $2.05(1.35,3.11)$ & $<0.001$ & $1.88(1.17,3.02)$ & 0.009 \\
\hline MASEI - soft tissue score & $1.65(1.07,2.53)$ & 0.022 & $1.52(0.96,2.41)$ & 0.07 \\
\hline \multicolumn{5}{|l|}{ Sacroiliitis } \\
\hline MASEl total & $1.36(1.10,1.70)$ & 0.005 & $1.33(1.03,1.72)$ & 0.027 \\
\hline MASEI - bone score & $2.12(1.42,3.16)$ & $<0.001$ & $2.24(1.40,3.61)$ & $<0.001$ \\
\hline MASEI - soft tissue score & $1.23(0.84,1.83)$ & 0.285 & $1.10(0.71,1.70)$ & 0.664 \\
\hline
\end{tabular}

MASEI MAdrid Sonography Enthesitis Index

* 10 units increase in MASEl

"*Each model was adjusted for age, sex, PsA duration, BMI, smoking, current use of DMARDs and biologics 
Table 4 The association between MASEI and mSASSS - negative binomial regression

\begin{tabular}{|c|c|c|c|c|c|c|}
\hline \multirow[t]{2}{*}{ Variable $^{*}$} & \multicolumn{3}{|c|}{ Univariate model } & \multicolumn{3}{|c|}{ Multivariable model $^{* *}$} \\
\hline & estimate (SE) & $\exp ^{\text {(Estimate) }}(95 \% \mathrm{Cl})$ & $P$ value & estimate (SE) & $\exp ^{\text {(Estimate) }}(95 \%$ Cl) & $P$ value \\
\hline MASEI - total & $0.65(0.25)$ & $1.92(1.17,3.09)$ & 0.009 & $0.78(0.32)$ & $2.18(1.16,4.09)$ & 0.02 \\
\hline MASEI - bone score & $1.23(0.42)$ & $3.42(1.52,7.69)$ & 0.003 & $1.51(0.51)$ & $4.52(1.68,12.18)$ & 0.003 \\
\hline MASEI - soft tissue score & $1.04(0.50)$ & $2.89(1.06,7.61)$ & 0.04 & $0.70(0.69)$ & $2.01(0.52,7.77)$ & 0.31 \\
\hline
\end{tabular}

MASEI MAdrid Sonography Enthesitis Index

* 10 units increase in MASEI

${ }^{* *}$ Each model was adjusted for age, sex, PsA duration, BMI, smoking, current use of DMARDs and Biologics

the degree of inflammation [19]. In accordance with these findings, our study found an association between the extent of enthesitis and peripheral joint damage.

However, there are studies that could not confirm the specific link between enthesitis and SpA [35, 36]. Paramarta et al. found the same prevalence of entheseal involvement in SpA and RA patients [35]. Ibrahim et al. found similar sonographic entheseal scores in patients with PsA and RA [36]. However, the significantly older age of the RA group in their study may have accounted for the higher entheseal score in this group leading to the similarity in scores. Overall, the discrepancies between the different studies can be attributed to the lack of standardization manifesting with diversity in several aspects including the type of the patients, the sample size, disease manifestations, enthesitis sites scanned, sonographic indices, and imaging equipment.

Unfortunately, there are only a few longitudinal studies that may address the controversy regarding the primacy of enthesitis in the pathogenesis of SpA [20,37]. Tinazzi et al. found that thickness of the quadriceps tendon predicated the development of clinical PsA in a small cohort of psoriasis patients [20]. El-Miedany et al. evaluated 126 psoriasis patients by clinical, radiological and sonographic measures over a period of 1 year [37]. However, this study did not differentiate between the two pathologies as it found that both sonographic enthesitis and synovitis at baseline were predictors of joint damage in new-onset PsA patients. Finally, a recent study in 41 psoriasis patients found that arthralgia and baseline MRI synovitis in the hand joints predicted the development of clinical PsA after 1 year of follow-up [38]. The detection of periarticular inflammation in only $4 \%$ of the patients raises a question regarding the reliability of this tool for enthesitis evaluation.

Enthesitis is a widespread condition that can involve the peripheral as well as the axial skeleton. The location of inflammation in spondylitis is at the entheses, where the ligaments attach to the vertebrae [39]. Several studies showed an association between clinical enthesitis [measured by the Maastricht Ankylosing Spondylitis Enthesis Score (MASES)] and both higher disease activity [measured by the Bath Ankylosing Spondylitis Disease Activity Index (BASDAI)] and worse functional status [40, 41]. In addition,
Muche et al. reported that enthesitis in the sacroiliac region, as detected by MRI, was more common in advanced sacroiliitis [42]. Our study found an association between sonographic enthesitis and axial damage, including both spondylitis and sacroiliitis. In contrast to our study, Alcalde et al. did not find a correlation between sonographic enthesitis and radiographic sacroiliitis [43]. However, their study is not entirely comparable to ours for several reasons: first, the study population included AS and not PsA patients, second, the sample size was much smaller including only 44 patients and lastly, the sonographic enthesitis index included less entheseal sites and did not include Power Doppler vascularization assessment.

The agreement between sonographic and clinical assessment of enthesitis is an area of interest in rheumatology due to the limited specificity and sensitivity of the latter method [15]. A few studies that compared these two modalities found low to moderate agreement [43, 44]. Recently, van der Ven et al. reported that adding US evaluation in psoriasis patients who had entheseal tenderness on clinical examination reduced the rate of enthesitis by $64 \%$ [45]. In this regard, it should be mentioned that the MASEI score includes entheseal lesions that represent irreversible damage from prior active enthesitis, such as enthesophytes and erosions, in addition to active lesions such as vascularization. Thus, the sonographic score may be high in patients who sustained entheseal damage from prior enthesitis who may be in remission at the time of assessment.

This study has several limitations. First, the association between sonographic enthesitis in sites located adjacent to large joints and radiographic damage of small joints in the hands and feet is indirect and may not suggest a causal link. Identifying enthesitis in the small joints is a difficult task, which may explain why there is no such enthesitis index. In addition, radiographic damage in large joints is less common and hence there is no standardized damage index for these sites. Thus, although the study cannot support a direct causal link between enthesitis and the development of peripheral or axial joint damage, the strong association observed between the extent of enthesitis and a number of features of joint damage in the peripheral and axial joints suggest that enthesitis may be a marker of more severe PsA phenotypes. 
An additional limitation of the study includes its crosssectional nature that does not allow making causal inferences. Furthermore, we assessed the associations between enthesitis at a single time point and radiographic damage that has accumulated over time. However, MASEI score includes a bone damage subcategory which reflects irreversible entheseal bone damage (e.g., enthesophytes and erosions) that has accumulated over time. Furthermore, all regression analyses showed that these chronic bone lesions were more strongly associated with radiographic joint damage than the soft tissue lesions. Lastly, treatments may have modified the relationship as we controlled for treatment only at the time of assessment, although it is expected that effective treatment for enthesitis, such as biologics, would have weakened the association. However, our sensitivity analyses that included the use of biologics and DMARDs at any point during the disease did not significantly modify the results.

This study has several strengths. To our knowledge, this is the largest study thus far that explored the association between sonographic enthesitis and radiographic joint damage in PsA. The use of sonographic enthesitis as a primary predictor improved the accuracy of assessing this important feature over physical examination [15]. In addition, the PsA cohort in this study is well phenotyped, which enables to control for multiple confounders.

\section{Conclusions}

The results of the study suggest that the severity of sonographic enthesitis is a potential marker of radiographic peripheral and axial joint damage in PsA. The association was found with both erosive and proliferative bone lesions. These findings raise the question of whether enthesitis has a role in the pathogenesis of articular damage in PsA. Further longitudinal studies in early PsA patients are required in order to establish the precise cause and effect relationships between enthesitis, synovitis, and joint damage.

\section{Abbreviations \\ AS: Ankylosing spondylitis; ASAS: Assessment of Spondyloarthritis International Group; BMI: Body mass index; CASPAR: Classification for psoriatic arthritis; $\mathrm{Cl}$ : Confidence interval; DMARDs: Disease-modifying antirheumatic drugs; GRAPPA: Group for Research and Assessment of Psoriasis and Psoriatic Arthritis; MASEl: MAdrid Sonography Enthesitis Index; MRI: Magnetic resonance imaging; mSASSS: modified Stoke Ankylosing Spondylitis Spine Score; mSS: modified Steinbrocker score; OR: Odds ratios; PASI: Psoriasis area and severity index; PsA: Psoriatic arthritis; RA: Rheumatoid arthritis; SpA: Spondyloarthritis; SPARCC: SPondyloArthritis Research Consortium Canada; US: Ultrasound}

\section{Acknowledgements}

Not applicable.

\section{Funding}

No funding was received for this study.

\section{Availability of data and materials}

The datasets used and/or analyzed during the current study are available from the corresponding author on reasonable request.

\section{Disclosures}

The University of Toronto Psoriatic Arthritis Program is supported by a grant from the Krembil Foundation. Ari Polachek was supported by an educational grant from Janssen Canada. Lihi Eder is supported by a New Investigator Salary Grant from the Arthritis Society and the Canadian Association of Psoriasis Patients. The authors declare that they do not have any potential conflicts of interests

\section{Authors' contributions}

AP contributed to study conception and design, analysis and interpretation of the data and preparation of the manuscript. RC contributed to analysis and interpretation of the data and preparation of the manuscript. VC contributed to study conception and design, analysis and interpretation of the data and preparation of the manuscript. DDG contributed to study conception and design, analysis and interpretation of the data and preparation of the manuscript. LE contributed to study conception and design, analysis and interpretation of the data and preparation of the manuscript. All authors read and approved the final manuscript.

\section{Ethics approval and consent to participate}

Research ethics board approval was obtained from the University Health Network, and consent was obtained from all study subjects.

\section{Consent for publication}

Not applicable.

\section{Competing interests}

The authors declare that they have no competing interests.

\section{Publisher's Note}

Springer Nature remains neutral with regard to jurisdictional claims in published maps and institutional affiliations.

\section{Author details}

${ }^{1}$ Centre for Prognostic Studies in the Rheumatic Diseases, Toronto Western Hospital, University of Toronto, 1-412, 399 Bathurst Street, Toronto, ON M5T 258, Canada. ${ }^{2}$ Department of Statistics and Actuarial Science, University of Waterloo, Waterloo, ON, Canada. ${ }^{3}$ Department of Medicine and Laboratory Medicine, Institute of Medical Science, University of Toronto, Toronto, ON, Canada. ${ }^{4}$ Department of Pathobiology, Institute of Medical Science, University of Toronto, Toronto, ON, Canada. ${ }^{5}$ Centre for Prognosis Studies in the Rheumatic Diseases, Krembil Research Institute, Toronto Western Hospital, Toronto, ON, Canada. ${ }^{6}$ Center for Prognostic Studies in the Rheumatic Diseases, Toronto Western Hospital, University of Toronto, Toronto, ON, Canada. 'Department of Medicine, University of Toronto, Women's College Research Institute, Women's College Hospital, Room 6326, 76 Grenville Street, Toronto, ON M5S 1B2, Canada.

Received: 8 June 2017 Accepted: 27 July 2017

Published online: 15 August 2017

\section{References}

1. Haroon M, Kirby B, FitzGerald O. High prevalence of psoriatic arthritis in patients with severe psoriasis with suboptimal performance of screening questionnaires. Ann Rheum Dis. 2013;72:736-40.

2. Ogdie A, Langan S, Love T, Haynes K, Shin D, Seminara N, et al. Prevalence and treatment patterns of psoriatic arthritis in the UK. Rheumatology (Oxford). 2013;52:568-75.

3. Gladman DD, Chandran V. Observational cohort studies: lessons learnt from the University of Toronto Psoriatic Arthritis Program. Rheumatol (Oxford). 2011;50:25-31.

4. Fournié B, Margarit-Coll N, Champetier de Ribes TL, Zabraniecki L, Jouan A, Vincent $V$, et al. Extrasynovial ultrasound abnormalities in the psoriatic finger. Prospective comparative power-doppler study versus rheumatoid arthritis. Joint Bone Spine. 2006;73:527-31.

5. Zabotti A, Salvin S, Quartuccio L, De Vita S. Differentiation between early rheumatoid and early psoriatic arthritis by the ultrasonographic study of the synovio-entheseal complex of the small joints of the hands. Clin Exp Rheumatol. 2016;34:459-65. 
6. Polachek A, Li S, Chandran V, Gladman D. Clinical enthesitis in a prospective longitudinal psoriatic arthritis cohort: incidence, prevalence, characteristics and outcome. Arthritis Care Res (Hoboken). 2016. Epub ahead of print.

7. Ranza R, Carneiro S, Qureshi AA, Martins G, Rodrigues JJ, Romiti R, et al. Prevalence of psoriatic arthritis in a large cohort of Brazilian patients with psoriasis. J Rheumatol. 2015:42:829-34.

8. Rahman P, Gladman DD, Cook RJ, Zhou Y, Young G, Salonen D. Radiological assessment in psoriatic arthritis. Br J Rheumatol. 1998;37:760-5.

9. Eshed I, Bollow M, Mcgonagle DG, Tan AL, Althoff CE, Asbach P. MRI of enthesitis of the appendicular skeleton in spondyloarthritis. Ann Rheum Dis. 2007:66:1553-9.

10. Poggenborg RP, Eshed I, Østergaard M, Sørensen IJ, Møller JM, Madsen OR. Enthesitis in patients with psoriatic arthritis, axial spondyloarthritis and healthy subjects assessed by 'head-to-toe' whole-body MRI and clinical examination. Ann Rheum Dis. 2015;74:823-9.

11. Gandjbakhch F, Terslev L, Joshua F, Wakefield RJ, Naredo E, D'Agostino MA. Ultrasound in the evaluation of enthesitis: status and perspectives. Arthritis Res Ther. 2011;13:R188.

12. Wiell C, Szkudlarek M, Hasselquist M, Møller JM, Vestergaard A, Nørregaard J. Ultrasonography, magnetic resonance imaging, radiography, and clinical assessment of inflammatory and destructive changes in fingers and toes of patients with psoriatic arthritis. Arthritis Res Ther. 2008;10:402.

13. Husic R, Gretler J, Felber A, Graninger WB, Duftner C, Hermann J. Disparity between ultrasound and clinical findings in psoriatic arthritis. Ann Rheum Dis. 2014;78:1529-36.

14. Balint PV, Kane D, Wilson H, Mclnnes IB, Sturrock RD. Ultrasonography of entheseal insertions in the lower limb in spondyloarthropathy. Ann Rheum Dis. 2002;10:905-10.

15. Zabotti A, Bandinelli F, Batticciotto A, Scirè CA, lagnocco A, Sakellariou G, Musculoskeletal ultrasonography for psoriatic arthritis and psoriasis patients: a systematic literature review. Rheumatol (Oxford). 2017. Epub ahead of print.

16. McGonagle D, Lories RJU, Tan AL, Benjamin M. The concept of a "SynovioEntheseal complex" and its implications for understanding joint inflammation and damge in psoriatic arthritis and beyond. Arthritis Rheum. 2007;56:2482-92

17. Lories RJ, Derese I, Luyten FP. Modulation of bone morphogenetic protein signaling inhibits the onset and progression of ankylosing enthesitis. J Clin Invest. 2005:115:1571-9.

18. Braem K, Carter S, Lories RJ. Spontaneous arthritis and ankylosis in male DBA/1 mice: further evidence for a role of behavioral factors in "stressinduced arthritis". Biol Proced Online. 2012;14:10.

19. Jacques P, Lambrecht $\mathrm{S}$, Verheugen E, Pauwels E, Kollias G, Armaka M, et al. Proof of concept: enthesitis and new bone formation in spondyloarthritis are driven by mechanical strain and stromal cells. Ann Rheum Dis. 2014;73:437-45.

20. Tinazzi I, McGonagle D, Biasi D, Confente S, Caimmi C, Girolomoni G, et al. Preliminary evidence that subclinical enthesopathy may predict psoriatic arthritis in patients with psoriasis. J Rheumatol. 2011:38:2691-2.

21. Eder L, Jayakar J, Thavaneswaran A, Haddad A, Chandran V, Salonen D, et al. Is the MAdrid Sonographic Enthesitis Index useful for differentiating psoriatic arthritis from psoriasis alone and healthy controls? J Rheumatol. 2014;41:466-72.

22. Taylor W, Gladman D, Helliwel P, Marchesoni A, Mease P, Mielants H. Classification criteria for psoriatic arthritis: development of new criteria from a large international study. Arthritis Rheum. 2006:54:2665-73.

23. Maksymowych WP, Mallon C, Morrow S, Shojania K, Olszynki WP, Wong RL, et al. Development and validation of the spondyloarthritis research consortium of Canada (SPARCC) enthesitis index. Ann Rheum Dis. 2009;68:948-63.

24. de Miquel E, Cobo T, Munoz-Fernandez S, Naredo E, Uson J, Acebes JC, et al. Validity of enthesis ultrasound assessment in spondyloarthropathy. Ann Rheum Dis. 2009;68:169-74.

25. Aydin SZ, Ash ZR, Tinazzi I, Castillo-Gallego C, Kwok C, Wilson C, et al. The link between enthesitis and arthritis in psoriatic arthritis: a switch to a vascular phenotype at insertions may play a role in arthritis development. Ann Rheum Dis. 2013;72:992-5

26. van der Linden S, Valkenburg HA, Cats A. Evaluation of diagnostic criteria for ankylosing spondylitis. A proposal for modifi cation of the New York criteria. Arthritis Rheum. 1984;27:361-8.

27. Spoorenberg A, de Vlam K, van der Linden S, Dougados $M$, Mielants $H$, van de Tempel $\mathrm{H}$, et al. Radiological scoring methods in ankylosing spondylitis, Reliability and change over 1 and 2 years. J Rheumatol. 2004;31:125-32.

28. Hilbe JM. Negative binomial regression, vol. 77 secondth ed. New York: Cambridge University Press; 2012. p. 611-2.
29. Ball J. Enthesopathy of rheumatoid arthritis and ankylosing spondylitis. Ann Rheum Dis. 1971;30:213-23.

30. McGonagle D, Gibbon W, Emery P. Classification of inflammatory arthritis by enthesitis. Lancet. 1998:352:1137-40.

31. Rudwaleit $M$, van der Heijde $D$, Landewé R, Listing J, Akkoc N, Brandt J, et al. The development of Assessment of SpondyloArthritis international Society classification criteria for axial spondyloarthritis (part II): validation and final selection. Ann Rheum Dis. 2009;68:777-83.

32. Rudwaleit M, van der Heijde D, Landewé R, Akkoc N, Brandt J, Chou CT, et al. The Assessment of SpondyloArthritis International Society classification criteria for peripheral spondyloarthritis and for spondyloarthritis in general. Ann Rheum Dis. 2011;70:25-31.

33. McGonagle D, Gibbon W, O'Connor P, Green M, Pease C, Emery P. Characteristic MRI entheseal changes of knee synovitis in spondyloarthropathy. Arthritis Rheum. 1998:41:694-700.

34. McGonagle D, Tan AL. The enthesis in psoriatic arthritis. Clin Exp Rheumatol. 2015;33(5 Suppl 93):S36-9.

35. Paramarta JE, van der Leij C, Gofita I, Yeremenko N, van de Sande MG, de Hair MJ, et al. Peripheral joint inflammation in early onset spondyloarthritis is not specifically related to enthesitis. Ann Rheum Dis. 2014;73:735-40.

36. Ibrahim G, Groves C, Chandramohan M, Beltran A, Valle R, Reyes B, et al. Clinical and ultrasound examination of the Leeds Enthesitis Index in psoriatic arthritis and rheumatoid arthritis. ISRN Rheumatol. 2011;2011: 731917.

37. El Miedany Y, El Gaafary M, Youssef S, Ahmed I, Nasr A. Tailored approach to early psoriatic arthritis patients: clinical and ultrasonographic predictors for structural joint damage. Clin Rheumatol. 2015;34:307-13.

38. Faustini F, Simon D, Oliveira I, Kleyer A, Haschka J, Englbrecht M, et al. Subclinical joint inflammation in patients with psoriasis without concomitant psoriatic arthritis: a cross-sectional and longitudinal analysis. Ann Rheum Dis. 2016;75(12):2068-74.

39. Hermann KG, Baraliakos X, van der Heijde DM, Jurik AG, Landewé R, MarzoOrtega $\mathrm{H}$, et al. Descriptions of spinal MRl lesions and definition of a positive MRI of the spine in axial spondyloarthritis: a consensual approach by the ASAS/OMERACT MRI study group. Ann Rheum Dis. 2012;71:1278-88.

40. Spadaro A, lagnocco A, Perrotta FM, Modesti M, Scarno A, Valesini G. Clinical and ultrasonography assessment of peripheral enthesitis in ankylosing spondylitis. Rheumatol (Oxford). 2011;50:2080-6.

41. Rezvani A, Bodur H, Ataman S, Kaya T, Buğdaycı DS, Demir SE. Correlations among enthesitis, clinical, radiographic and quality of life parameters in patients with ankylosing spondylitis. Mod Rheumatol. 2014;24:651-6.

42. Muche B, Bollow M, François RJ, Sieper J, Hamm B, Braun J. Anatomic structures involved in early- and late-stage sacroiliitis in spondylarthritis: a detailed analysis by contrast-enhanced magnetic resonance imaging. Arthritis Rheum. 2003;48:1374-84.

43. Alcalde M, Acebes JC, Cruz M, González-Hombrado L, Herrero-Beaumont G, Sánchez-Pernaute O. A sonographic enthesitic index of lower limbs is a valuable tool in the assessment of ankylosing spondylitis. Ann Rheum Dis. 2007;66:1015-9.

44. Hamdi W, Chelli-Bouaziz M, Ahmed MS, Ghannouchi MM, Kaffel D, Ladeb MF, et al. Correlations among clinical, radiographic, and sonographic scores for enthesitis in ankylosing spondylitis. Joint Bone Spine. 2011;78:270-4.

45. van der Ven M, Karreman MC, Weel AE, Tchetverikov I, Vis M, Nijsten TE, Hazes JM, et al. Adding ultrasound to clinical examination reduced frequency of enthesitis in primary care psoriasis patients with musculoskeletal complaints. Clin Exp Rheumatol. 2016;34:1020-25.

\section{Submit your next manuscript to BioMed Central and we will help you at every step:}

- We accept pre-submission inquiries

- Our selector tool helps you to find the most relevant journal

- We provide round the clock customer support

- Convenient online submission

- Thorough peer review

- Inclusion in PubMed and all major indexing services

- Maximum visibility for your research

Submit your manuscript at www.biomedcentral.com/submit 